\title{
It Depends': A qualitative study on how adolescent students explain bystander intervention and non-intervention in bullying situations
}

Robert Thornberg, Lena Landgren and Erika Wiman

The self-archived postprint version of this journal article is available at Linköping University Institutional Repository (DiVA):

http:/ / urn.kb.se/ resolve?urn=urn:nbn:se:liu:diva-150218

N.B.: When citing this work, cite the original publication.

Thornberg, R., Landgren, L., Wiman, E., (2018), It Depends': A qualitative study on how adolescent students explain bystander intervention and non-intervention in bullying situations, School Psychology International, 39(4), 400-415. https:// doi.org/ 10.1177/ 0143034318779225

Original publication available at:

https:// doi.org/ 10.1177/ 0143034318779225

Copyright: SAGE Publications (UK and US)

http:// www.uk.sagepub.com/home.nav 
"It Depends": A Qualitative Study on How Adolescents Students Explain Bystander Intervention and Non-Intervention in Bullying Situations

\author{
Robert Thornberg \\ Lena Landgren \\ Erika Wiman \\ Linköping University, Sweden
}

Corresponding author: Robert Thornberg, PhD, Professor, phone: 4613 282118, e-mail: robert.thornberg@liu.se, address: Department of Behavioral Sciences and Learning, Linköping University, SE-58183 Linköping, SWEDEN 


\begin{abstract}
The aim of the current study was to examine how junior high school students interpret, motivate and explain various bystander behaviors in bullying situations. The participants were 17 junior high school students recruited from four schools in Sweden. Semi-structured interviews were conducted and analyzed with grounded theory methods. The analysis generated a conceptual model of bystander interpreting-considering process in school bullying. A core category named "it depends" was developed to explain how the participants in the study motivated their and their peers' actions as bystanders in various bullying situations. Whether they intervened or not depended on how they interpreted the situation in terms of: (a) seriousness of the situation, including trivialization, (b) social relationships with the involved, (c) locus of responsibility, including displacement of responsibility, and victim blame, (d) social status, (e) perception of risk, and (f) defender self-efficacy. The implications of these results for bullying prevention and intervention efforts are discussed.
\end{abstract}

Keywords: bullying, bystander, defender, displacement of responsibility, victim blame 
"It Depends": A Qualitative Study on How Adolescents Explain Bystander Intervention and Non-Intervention in Bullying Situations

School bullying is a social phenomenon embedded in a social context in which peers are most often present as bystanders (e.g., Craig, Pepler, \& Atlas, 2000). Paying attention to students' perspectives on bystander behaviors is important, since between-classroom variability in bullying prevalence can be explained in part by the prevalence of bystander behaviors (Salmivalli, Voeten, \& Poskiparta, \& 2011). According to the new sociology of childhood (James \& Prout, 1997), children and adolescents are not just passive recipients but actually active agents in their socialization process. They are both constrained by structure and at the same time active agents acting in and upon structure. They produce local peer cultures as a result of their attempts to make sense of, and even to resist, the adult world (Corsaro, 2005).

Research on bystander behavior in school bullying has usually been conducted by using quantitative methods and has demonstrated how a range of variables are associated with various bystander behaviors (e.g., Li, Chen, Chen, \& Wu, 2015; Pöyhönen, Juvonen, \& Salmivalli, 2012; Pozzoli \& Gini, 2013; Song \& Oh, 2017). According to Bosacki, Marini, and Dane (2006), quantitative research provides a great deal of critical information about bullying but "does not give children an opportunity to discuss their own understanding of bullying experiences in their own voices" (p. 232). Qualitative methods offer important insights regarding the insider's perspectives (Patton, Hong, Patel, \& Kral, 2017).

There are, however, still only a few studies that have explored students' perspectives on bystander behaviors: Swedish students in middle childhood (Forsberg et al., 2014; cf., Thornberg, 2007, 2010), Taiwanese students in adolescence (Chen et al., 2016), and US and Swedish students in middle childhood and adolescence but without analyzing possible differences and similarities across age (Forsberg et al., 2018; Thornberg et al., 2012). 
Together, these studies have indicated that students' willingness to defend bullying victims depends on their interpretation of the seriousness of the situation, how they feel themselves in the situation, their relationships with bullies and victims, the social status of bullies and their own social status, in what ways they attribute cause and responsibility to the victim, and their perceived ability to intervene and defend the victim.

However, whereas adolescents' perspectives on bystander behaviors have been explicitly examined within an Asian cultural context (southern Taiwan) in one published study, qualitative research aimed to explore how adolescents as a distinct age group within a Western cultural context, interpret, motivate and explain various bystander behaviors is still missing. We cannot take for granted that how students interpret and reason about how to react and act as bystanders in bullying is the same across age groups and cultural contexts. Further qualitative studies on adolescents' perspectives on bystander behavior in bullying are therefore still needed. The aim of the current study was to examine how junior high school students (i.e., students in adolescence) in a Western cultural context (i.e., Sweden) interpret, motivate and explain various bystander behaviors in bullying situations.

\section{Method}

\section{Participants}

To recruit participants for this study, 67 junior high school students located in various schools in the eastern part of Sweden filled out an online questionnaire, in which they reported if they had own experiences of witnessing bullying at school (which were an inclusion criterion for participating in the study) and if they consented to participate in the interview study. Those who gave their consent were asked to give their contact information. As a result of this procedure, 17 Swedish junior high school students (11 females; age range = 13-15 years old, $M=13.8$ ) participated. We obtained parental consent and student assent from all participating students. The participants came from four different schools located in various 
socio-geographic areas (one public school in the countryside, one public school in a small Swedish town, and two private schools in different neighborhoods of a medium-sized Swedish city). Fourteen of the participants had a Swedish ethnic background. Approval from the Regional Ethical Review Board was obtained prior to all data collection.

\section{Interviews}

Individual qualitative semi-structured interviews were conducted in a quiet room in the school setting but away from the classroom. Three Master's students in Psychology (the second and third authors, and an additional Master's student in Psychology) carried out the interviews. They received instructions and training in qualitative interviewing from the first author. In total, 20 interviews were conducted. First, all participants were interviewed once, resulting in 17 interviews ranging from 19 to 46 minutes $(M=28, S D=0.65)$. The students were asked to explain more about their experiences of witnessing bullying reported in the online questionnaire. They were asked to report the bullying situations more in detail, what happened and why they thought it happened, if other students were present, how they reacted, what they did and why they did it. Then, the participants were asked about their own reactions as bystanders, what they did, why they did what they did, and what they thought and felt.

In line with grounded theory (Charmaz, 2014), data collection and analysis took place in parallel, and this iterative process guided the interviewers (theoretical sampling) and made the interviews more focused over time. As a further result of theoretical sampling, and to reach theoretical saturation (Charmaz, 2014), three of the 17 participants were selected for shorter follow-up interviews ranging from 7 to 12 minutes $(M=10)$. In the follow-up interviews, the participants were asked about emerging themes and categories. The interviewers avoided the position of authority and took an atypical, less power-oriented, adult research role in accordance with the "least-adult role" (Mandell, 1991), including the adoption of a non-judgmental approach. At the end of each interviews, the interviewers informed the 
participants about the anti-bullying and/or student health team in the local school and how to get in contact with them, but also about BRIS (the Swedish child helpline), including giving them a BRIS card with contact information. Each interview was audio-recorded and transcribed verbatim by the person who conducted the interview.

\section{Analysis}

We adopted a constructivist grounded theory approach (Charmaz, 2014), and used grounded theory methods to explore and analyze data. Coding (creating codes and categories grounded in data), constant comparison (comparing data with data, data with codes, codes with codes, data with categories and so on), memo writing (writing down ideas about relationships between codes and other theoretical ideas that come to mind during the coding and analysis), and memo sorting (comparing and sorting our memos) were the main methods in the current study. Furthermore, during the analysis, pre-existing theoretical concepts from the literature were selected and used as "lenses" and tools based on their fit and relevance with the data as they helped us to focus our attention on certain phenomena, aspects and nuances, very much in line with the logic of abduction (Thornberg, 2012). In line with a constructivist grounded theory, code names were sometimes created in vivo and sometimes taken from the literature as a result of the interplay between induction and abduction and in order to remain open and sensitive to data without "re-inventing the wheel".

During the initial coding, the second and third authors coded different interview transcriptions independently of each other, and then compared and discussed their developed codes and their relation to data. They discussed them and when they found it necessary, they elaborated them until a consensus was reached. They conducted focused- and theoretical coding together. The first author then critically scrutinized and elaborated their work and completed the theoretical coding in dialogue with them. Hence, the trustworthiness of the coding was accomplished through critical dialogue procedures within the research team. 


\section{Results}

\section{"It Depends"}

A core category named "it depends" was developed to explain how the participants in the study motivated their own actions and their peers' actions as bystanders in various bullying situations. Whether they intervened or not depended on how they interpreted the situation in terms of: (a) seriousness of the situation, including trivialization, (b) social relationships with the involved, (c) locus of responsibility, including displacement of responsibility, and victim blame, (d) social status, (e) perception of risk, and (f) defender self-efficacy. The core category "it depends" is illustrated in the excerpt below.

Interviewer: In a situation like this, when they are doing this towards another student, what do those around usually do?

Rasmus: It may depend on who it is. It may also depend, well, it's probably mostly about who it actually is because sometimes it could in fact be that, like a kind of situation in the past when some were messing with my friend /.../ and then I told them /.../It depends on how gross it is /.../ It's from situation to situation. Who it is. Who, or how many they are, and if you're together with someone else - if I'm standing there alone or if one of my friends is standing behind me and kind of supporting me. It's also about how many I'm facing. Is it one person bullying someone or are there five people attacking the person, and I'm somehow alone against those five.

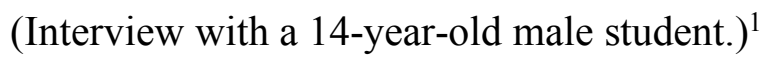

\footnotetext{
1 The interview excerpts in the article have been translated from Swedish into English by the first author, and the translations have then been reviewed by an independent proof-reader.
} 
As in the excerpt above, the students reported how various factors in the bullying situation were considered and influenced their own bystander behaviors and those of their peers. A conceptual model of a bystander interpreting-considering process in school bullying is shown in Figure 1. This conceptual model represents how students' interpreting-considering process in the bullying situation motivates and contributes to explaining the degree of willingness to intervene from students' perspectives.

- Insert Figure 1 about here -

\section{"Should Help": The Moral Starting Point}

Several students claimed that bullying is wrong and should not take place at school or elsewhere (e.g., "Well, everyone realizes that bullying is wrong", Felicia, 14-year-old female student). They also argued that they and other peers should help the victim if they were witnessing bullying.

I think everyone should intervene and try to help, and personally I think that you become cooler if you try to help someone else than if you're harming someone. (Rebecca, 13-year-old female student.)

The analysis of the interview data suggested that there seemed to be a moral starting point among the students in which they think that bystanders should intervene and help the victim of bullying. At the same time, the students reported that peers were present as bystanders in most school bullying cases, and the majority of them did not intervene (cf., Craig et al., 2000).

\section{Seriousness of the Situation}

How serious a bystander perceives a bullying situation to be will influence whether or not they intervene. "It depends on how bad it is, if it's just someone standing there and talking or if someone is really mean towards someone else" (Moa, 14-year old female student). They 
will be more inclined to intervene when the bullying incident is serious. Physical bullying was often mentioned as being more serious than other forms of bullying. Moreover, students reasoned that joke-like characteristics in bullying situations risk influencing bystanders to interpret the whole situation as a non-serious, harmless joke, particularly if the victim is laughing and playing along with the perpetrators. "I don't know where to draw the line, what's mean and what's nice, and if they're just joking. Sometimes you don't know if people are joking or not. It's hard to know, and sometimes you listen during the breaks and that, and then you might laugh" (Lisa, a 14-year old female student). Many students talked about a grey zone between joking and seriousness that made it hard to interpret the degree of seriousness and whether intervention was needed.

\section{Trivialization}

Interpreting a bullying situation as a non-serious situation can be understood as what Thornberg (2007) labelled trivialization, which refers to "a definition of the critical event as trivial and not an emergency situation" (p. 13), which could happen when the situation is defined as a harmless “joking” situation but also when bystanders interpret and define the situation as an ordinary or familiar event as if everything in the situation is normal and business as usual. Many students reported that peer victimization was so common in everyday school life that they did not always react to it.

If I would do a thing towards someone and then like, "no, this isn't nice", but if I do things repeatedly towards someone, kind of victimizing, then it could be like, oh, it's just a... nowadays we're just more like kidding. So, if I say something mean to someone several times, like "you're ugly" and "haha", then it became like, "well, I’ve always done this". Nowadays, kids are kidding more about that and about bullying. (Emma, 13-year-old female student) 
According to Emma, repeated negative behavior, which is a characteristic of bullying (Olweus, 1993), might in itself lead peers to trivialize this bullying pattern because it is happening so often and has become a part of normal life, in particular if many peers do it. ("Usually, you don't react whatsoever because almost everyone does it", Veronica, a 13-yearold female student.) When bullying has been trivialized, there are no reasons for bystanders to intervene because the situation is interpreted as a harmless non-serious situation.

\section{Social Relationships with those Involved}

Another recurrent pattern in the interview data was that the students reported that whether they would intervene or not as bystanders in bullying situations often depended on their relationships with those involved in bullying. They would be more inclined to try to stop bullying if the victim was their friend (e.g., "Sometimes I interfere if it's my friends, otherwise I kind of don't care", Johan, a 13-year-old male student). Some participants reported that if the bully was their friend, they would either remain passive (being loyal to the bully and simple blaming the victim) or try to reason with the bully in an effort to stop the bullying as they argued that it would be easier to tell the bully to stop if he or she was their friend.

Felicia: Well, it's much easier if my friends are those who're fighting [with the victim] because I would be better at stopping them since I know them, you know.

Interviewer: Alright, what would be easier if you know the people?

Felicia: Well, it kind of feels like they're listening much more to what you're telling them.

(Interview with a 14-year-old female student)

\section{Displacement of Responsibility}


Displacement of responsibility (Bandura, 1999) emerges when bystanders displace their own responsibility to intervene away from themselves and instead put the responsibility on others. The most reported responsibility transfer was to place the responsibility on the teachers. The students argued that the teachers had a responsibility to prevent bullying and to intervene and stop bullying at school.

Interviewer: What reasons do you think mean that people don't do that, I mean don't speak up and check it out?

Emma: Because you kind of think that someone else will take care of it, yeah, some teacher. They say that they see everything and, well, then they see this. Or they might be busy on their way somewhere and you think, "It's surely just today".

(Interview with a 13-year-old female student)

In addition, many students also argued that those who are friends with the victim have a greater responsibility to intervene than other peers. They claimed that this principle guided their own action and that they were more inclined to directly intervene if they were friends with the victim. In this way, the responsibility was transferred to the victim's friends.

It depends on if it's your friend as well. I mean, if it's your friend, you might just say something like, "No, stop that! It's mean!” And then walk away and tell your friend that maybe she should tell a teacher or something. Otherwise, I really don't know. If it wasn't someone you know, then you perhaps would more or less ignore it. (Moa, 14year-old female student)

\section{Victim Blame}


Victim blame refers to attributing the cause of bullying to the victim and therefore also blaming the victim for the bullying. Some of the students argued that the victim might have done something bad towards someone else, which in turn leads to other peers thinking that the victim has to blame herself or himself for being victimized, and therefore do not intervene.

They don't like her, and that's rather understandable as I don't like this person either, but they probably thought that this person had written something mean about them /.../ they probably thought that they had the right /.../ because mean things were written about them and they were angry towards this person. (Veronica, 14-year-old female student)

It sounds terrible but he's-, this person has an ability to be rather annoying and I don't know why, but it's probably to assert himself that he tries to be annoying, and kind of trying to disturb others. So, what happens is that everyone kind of gets a little angry with him, and because he does this to almost everyone, he will have trouble with-, that no one will stand up for him because he will not be liked. (Rasmus, 14-year-old male student)

The excerpt above illustrates students' proneness to remain passive bystanders if they dislike the victims and think the victims have themselves to blame because of their annoying personality or manner.

\section{Social Status}

Several students in the current study reported that if their own social status was higher than that of the bullies, they would be more willing to intervene, but if their social status was lower than that of the bullies, they would be less inclined to intervene. 
Interviewer: Are there any situations in which it would be easier to stand up for someone?

Johan: Hu-huh!

Interviewer: What kind of situations could that be?

Johan: If it's a person [the bully] /.../ who isn't that popular, then he kind of can't do anything.

Interviewer: Okay, and in which situations could it be more difficult?

Johan: Well, if they [the bullies] are kind of more popular, then you could get attacked by several of them.

(Interview with a 13-year-old male student)

Intervening with a lower status than powerful and high-status bullies was associated with a perceived risk and fear of being victimized, which inhibits bystander intervention.

\section{Perception of Risk}

How bystanders act in a bullying situation is also dependent on how risky or dangerous they interpret intervening to be. The majority of the students reported that they would probably remain passive and try to stay outside the situation if they perceive a high risk of being seriously attacked or even bullied themselves by the perpetrator(s) if they intervene. In other words, a fear of being victimized inhibits bystanders from intervening. Some of the students stated that the risk of being victimized is particularly high if the perpetrator has a higher social status compered to themselves or if they perceive that all the other bystanders are on the bullies' side.

Interviewer: You said that you often really don't want to tell [the bully]. How come? What do you think? 
Sophia: I don't know. You're kind of afraid of the one [the bully] who said that, or like if everyone else thinks that it's fun and you don't think it's fun and that they would kind of judge you. It depends on who you are as a person and what kind of status you have in the school class or in the group. Those who don't say much and have little, I mean-, depend on the others, like, maybe don't say much, while if there is a person with a little higher status and who dares to say something, then this person might speak out more or more often.

(Interview with a 15-year-old female student)

In addition, a fear of being judged by present peers inhibits intervention. Although it was usually considered to be safer than direct intervention, indirect intervention such as telling a teacher could, according to several students, still be considered as a risk in terms of the risk of being perceived as a squealer. "Well, many people think that you wouldn't like to be called a squealer because you will not be popular, or how to put it, in the classroom" (Hanna, 13-year-old female student).

\section{Defender Self-Efficacy}

Strong beliefs in one's ability to intervene successfully in bullying situations (defender self-efficacy) make bystanders more willing to intervene, whereas poor defender self-efficacy inhibits them from intervening. Defender self-efficacy seems to be dependent on several aspects, according to the students.

Interviewer: Have you been in a situation in which you have felt that you want to speak up? 
Moa: It was when someone was a kind of mean to my sis, then I just said, "Stop doing that!"

Interviewer: What happened then?

Moa: Well, it was someone older but I was even older than that person so I just walked up to her and said, "No, stop that!"

(Interview with a 14-year-old female student)

Instead of being something static and fixed, their defender self-efficacy was rather situated and context-dependent. Higher social status, older age and outnumbering the bully or the bullies were associated with a stronger belief in the ability to intervene and defend the victim, which could vary across situations.

Interviewer: You said that you used to tell [the bullies] if you hear anything, but are there any situations where you think it's difficult to tell them?

Oscar: Well, if there are many against one, or many attacking a few, then it's a little more difficult to stand up for the victims.

(Interview with a 14-year-old male student)

\section{Discussion}

The present study contributes to the small but growing research body on students' perspectives on bystander behavior in school bullying, supporting several previous findings. Our study is, as far as we know, the first to exclusively examine how adolescents in a Western cultural context (Sweden) interpret, motivate and explain various bystander behaviors. Its current findings can therefore be compared with how adolescents in an Asian cultural context (in southern Taiwan; Chen et al., 2016), younger students (in middle childhood) in a Western cultural context (in Sweden; Forsberg et al., 2012), and American and Swedish students in 
middle childhood and adolescence (but in which possible age similarities and differences were not analyzed; Forsberg et al., 2018; Thornberg et al., 2012) reasoned about bystander behavior in prior qualitative studies.

Although the students in the current study argued that bullying is wrong and that bystanders should intervene, as the younger students in Forsberg and colleagues' (2012) study did, if the actual situation is not perceived as a serious situation, there is no reason to intervene. Students' emphasis on the seriousness of the situation supports previous studies (e.g., Chen et al., 2016; Forsberg et al., 2014; Thornberg et al., 2012), and echoes the early and conditional steps in Latené and Darley's (1970) decision model of bystander intervention (noticing that something is wrong and deciding the event is an emergency). Physical bullying was considered to be more serious than other forms of bullying, which confirms previous studies as well (Chen et al., 2016; Forsberg et al., 2014; Forsberg et al., 2018).

Another important finding in the current study is bystanders' considerations of their relationships with those involved and the locus of responsibility. Witnessing a serious situation in which the victim is harmed evokes a sense of personal responsibility to intervene ("Should help": The moral starting point). Furthermore, if bystanders consider the victims as their friends, they seem to be even more inclined to perceive a personal responsibility to intervene, which has also been found in previous qualitative studies (Chen et al., 2016; Forsberg et al., 2014; Thornberg et al., 2016; Thornberg et al., 2012). If bystanders consider the bullies as their friends, they would be less willing to help the victims and even more willing to take the bullies' side, according to some studies (Forsberg et al., 2014; Thornberg et al., 2012). However, the current findings nuance this picture by revealing that this seems to be more double-edged from students' points of view. On one hand, being a friend of the bully could indeed inhibit bystanders from intervening, as found in previous studies, based on loyalty and blaming the victim. On the other hand, some of the students in the present study 
reported that being a friend of the bully could actually make bystanders feel more responsible and inclined to intervene by trying to reason with the bully in efforts to stop the bullying, simply because they know them.

According to Latené and Darley’s (1970) decision model of bystander intervention, if bystanders interpret that something is wrong and the event is an emergency, they still have to decide on their degree of personal responsibility. The current study identified some processes that lower the sense of personal responsibility to intervene, in addition to not being considered as a friend to the victim. A moral disengagement mechanism that emerged in the current study was displacement of responsibility (Bandura, 1999), in particular by displacing responsibility to teachers but also to the victim's friends. Another moral disengagement mechanism found in the current study was blaming the victim (Bandura, 1999), which reduces the sense of personal responsibility to intervene since the victim is considered to be responsible for his or her own situation. The relationship between victim blame and non-intervention in bullying has also been found in previous qualitative studies (e.g., Chen et al., 2016; Forsberg et al., 2014; Thornberg et al., 2012) and quantitative studies (Gini, Pozzoli, Borghi, \& Franzoni, 2008; Thornberg \& Jungert, 2014).

In the present study, social status, perception of risk, and defender self-efficacy were more or less interrelated. Bystanders consider the social status of the bullies and in relation to their own social status, and if their own status was lower that the bully or the bullies, bystanders were less inclined to defend the victim, according to the students. This has also been shown in other studies (Forsberg et al., 2014; Thornberg et al., 2012), and is an important finding since bullying has been linked in several studies to social status, dominance and popularity, in which bullies tend to have a high social status (e.g., de Bruyn, Cillessen \& Wissink, 2010). Trying to help victims in front of bullies who are more powerful and had a higher status than the bystander was associated with a perceived risk, particularly in terms of 
a fear of being victimized. The majority of the students reported that they would probably remain passive and try to stay outside in such situations. Thus, the power imbalance in bullying (Olweus, 1993) seems to be extended beyond the bully-victim dyad to also include and inhibit bystanders with less power and social status than the bully.

In contrast, defender self-efficacy was linked to intervention, which supports previous qualitative studies on students' perspectives (Chen et al., 2016; Forsberg et al., 2018; Thornberg et al., 2012) as well as quantitative studies (Barchia \& Bussey, 2011; Pöyhönen et al., 2012). Being perceived as more powerful and having a higher social status than the bullies were considered by the students as a source for a stronger belief in the ability to intervene and defend the victim, which in turn supports Bandura's (1997) idea that self-efficacy is situated and context-depended, and thus more adequate than global constructs like self-esteem and self-confidence in order to understand bystander behavior in school bullying. Our findings add a student perspective showing that adolescents consider higher social status, older age and outnumbering the bully or the bullies as factors that enhance their beliefs in their capacity to defend a victim in bullying.

\section{Limitations}

Some notes of caution need to be sounded regarding the present findings. First, the results rely on interview data which can be problematized in terms of ecological validity (i.e., what students say they and their peers do during an interview setting and what they and their peers actually do in their everyday real-life setting would not necessarily be the same). However, in line with a constructivist position of grounded theory, we do not claim to offer an exact picture but rather an interpretive portrayal of the phenomenon studied (Charmaz 2014). Second, this sample of junior high school students from a particular area of Sweden may or may not be similar to the population of students with whom the readers primarily work or are interested in. The vast majority of the students in the current study had a Swedish ethnic 
background, which could be compared with other qualitative studies on bystander behavior in which ethnic minorities were under-represented and marginalized (Forsberg et al., 2018; Thornberg et al., 2012) or not mentioned at all (Chen et al., 2016; Forsberg et al., 2014). Future research needs to examine how students interpret, motivate and explain different bystander behaviors in bullying might be linked to gender, ethnicity (cross-culturally as well as majority/minority group membership within cultures), socio-economic background and socio-geographic location.

\section{Practical Implications}

The current study has implications for bullying prevention and intervention efforts. First, because students are not willing to intervene if they do not perceive a bullying incident as serious, school psychologists and teachers need to help students to understand the severe harm in all forms of bullying, to counteract trivialization, and to make a clear distinction between joking and harming someone. Second, to enhance bystander intervention among students, school psychologists and teachers have to emphasize students' personal responsibility and make them aware of and reduce moral distortions like displacement of responsibility and victim blame. Third, school psychologists and teachers need to be aware of how the imbalance in power and social status between bullies and bystanders affects bystanders' perception of risk, fear of being victimized, defender self-efficacy, and willingness to intervene. Efforts should be focused on equality and collective efficacy, i.e., a shared belief that students and teachers can work together to efficiently stop aggression (Barchia \& Bussey, 2011).

Finally, our study encourages school psychologists to listen to students, made efforts to examine their understandings and involve them in bullying prevention. Instead of excluding young people from the processes of dialogue and decision-making, we need to consult them due to their experiences and expertise of being students in the local school and to invite them 
to participate and have a voice in the school's efforts to combat bullying. Student consultation and participation are crucial because students are more knowledgeable about what goes on in the playground and the corridors (Rudduck \& Flutter, 2004). Findings from the current study can be used as a starting point when examining the adolescents' perspectives and giving them a voice in bullying prevention in the local school. 


\section{References}

Bandura, A. (1997). Self-efficacy: The exercise of control. New York, NY: W. H. Freeman and Company.

Bandura, A. (1999). Moral disengagement in the perpetration of inhumanities. Personality and Social Psychology Review, 3, 193-209.

Barchia, K., \& Bussey, K. (2011). Predictors of student defenders of peer aggression victims: Empathy and social cognitive factors. International Journal of Behavioral Development, 35, 289-297.

Bosacki, S. L., Marini, Z. A., \& Dane. A. V. (2006). Voices from the classroom: Pictorial and narrative representations of children's bullying experiences. Journal of Moral Education, $35,231-245$.

Charmaz, K. (2014). Constructing grounded theory (2 $2^{\text {nd }}$ ed.). London: Sage.

Chen, L-M., Chang, L. Y. C., \& Cheng, Y-Y. (2016). Choosing to be a defender or an outsider in school bullying incident: Determining factors and the defending process. School Psychology International, 37, 289-302.

Corsaro, W. A. (2005). The sociology of childhood (2nd ed.). Thousand Oaks, CA: Pine Forge Press.

Craig, W. M., Pepler, D. J., \& Atlas, R. (2000). Observations of bullying in the playground and in the classroom. School Psychology International, 21, 22-36.

de Bruyn, E. H., Cillessen, A. H. N., \& Wissink, I. B. (2010). Associations of peer acceptance and perceived popularity with bullying and victimization in early adolescence. Journal of Early Adolescence, 30, 543-566.

Forsberg, C., Thornberg, R., \& Samuelsson, M. (2014). Bystanders to bullying: Fourth- to seventh-grade students' perspectives on their reactions. Research Papers in Education, 29, 557-576. 
Forsberg, C., Wood, L., Smith, J., Varjas, K., Meyers, J., Jungert, T., \& Thornberg, R. (2018). Students' views on factors affecting their bystander acts in bullying situations: A crosscollaborative conceptual qualitative analysis. Research Papers in Education, 3, 127-142.

Gini, G., Pozzoli, T., Borghi, F., \& Franzoni, L. (2008). The role of bystanders in students' perception of bullying and sense of safety. Journal of School Violence, 46, 617-638.

James, A. \& Prout, A. (Eds.) (1997). Constructing and reconstructing childhood (2 ${ }^{\text {nd }}$ ed.). London: Falmer.

Latené, B., \& Darley, J. M. (1970). The unresponsive bystander: Why doesn't he help? New York, NY: Meredith.

Li, Y., Chen, P. Y., Chen, F-L., \& Wu, W-C. (2015). Roles of fatalism and parental support in the relationship between bullying victimization and bystander behaviors. School Psychology International, 36, 253-267.

Mandell, N. (1991). The least-adult role in studying children. In F. C. Walker (Ed.), Studying the social worlds of children: Sociological readings (pp. 38-59). London: Routledge Falmer.

Olweus, D. (1993). Bullying in school. Cambridge, MA: Blackwell.

Patton, D. U., Hong, J. S., Patel, S., \& Kral, M. J. (2017). A systematic review of research strategies used in qualitative studies on school bullying and victimization. Trauma, Violence, \& Abuse, 18, 3-16.

Pöyhönen, V., Juvonen, J., \& Salmivalli, C. (2012). Standing up for the victim, siding with the bully or standing by? Bystander responses in bullying situations. Social Development, $21,686-703$.

Pozzoli, T., \& Gini, G. (2013). Why do bystanders of bullying help or not? A multidimensional model. The Journal of Early Adolescence, 33, 315-340. 
Rudduck, J. \& Flutter, J. (2004). How to improve your school: Giving pupils a voice. London: Continuum.

Salmivalli, C., Voeten, M., \& Poskiparta, E. (2011). Bystanders matter: Associations between reinforcing, defending, and the frequency of bullying behavior in classrooms. Journal of Clinical Child \& Adolescent Psychology, 40, 668-676.

Song, J., \& Oh, I. (2017). Investigation of the bystander effect in school bullying: Comparison of experiential, psychological and situational factors. School Psychology International, 38, 319-336.

Thornberg, R. (2007). A classmate in distress: Schoolchildren as bystander and their reasons for how they act. Social Psychology of Education, 10, 5-28.

Thornberg, R. (2010). A student in distress: Moral frames and bystander behavior in school. The Elementary School Journal, 110, 585-608.

Thornberg, R. (2012). Informed grounded theory. Scandinavian Journal of Educational Research, 56, 243-259.

Thornberg, R., \& Jungert, T. (2014). School bullying and the mechanisms of moral disengagement. Aggressive Behavior, 40, 99-108.

Thornberg, R., Tenenbaum, L., Varjas, K., Meyers, J., Jungert, T., \& Vanegas, G. (2012). Bystander motivation in bullying incidents: To intervene or not? Western Journal of Emergency Medicine, 13, 247-252. 
Figure 1. A conceptual model of bystander interpreting-considering process in school bullying.

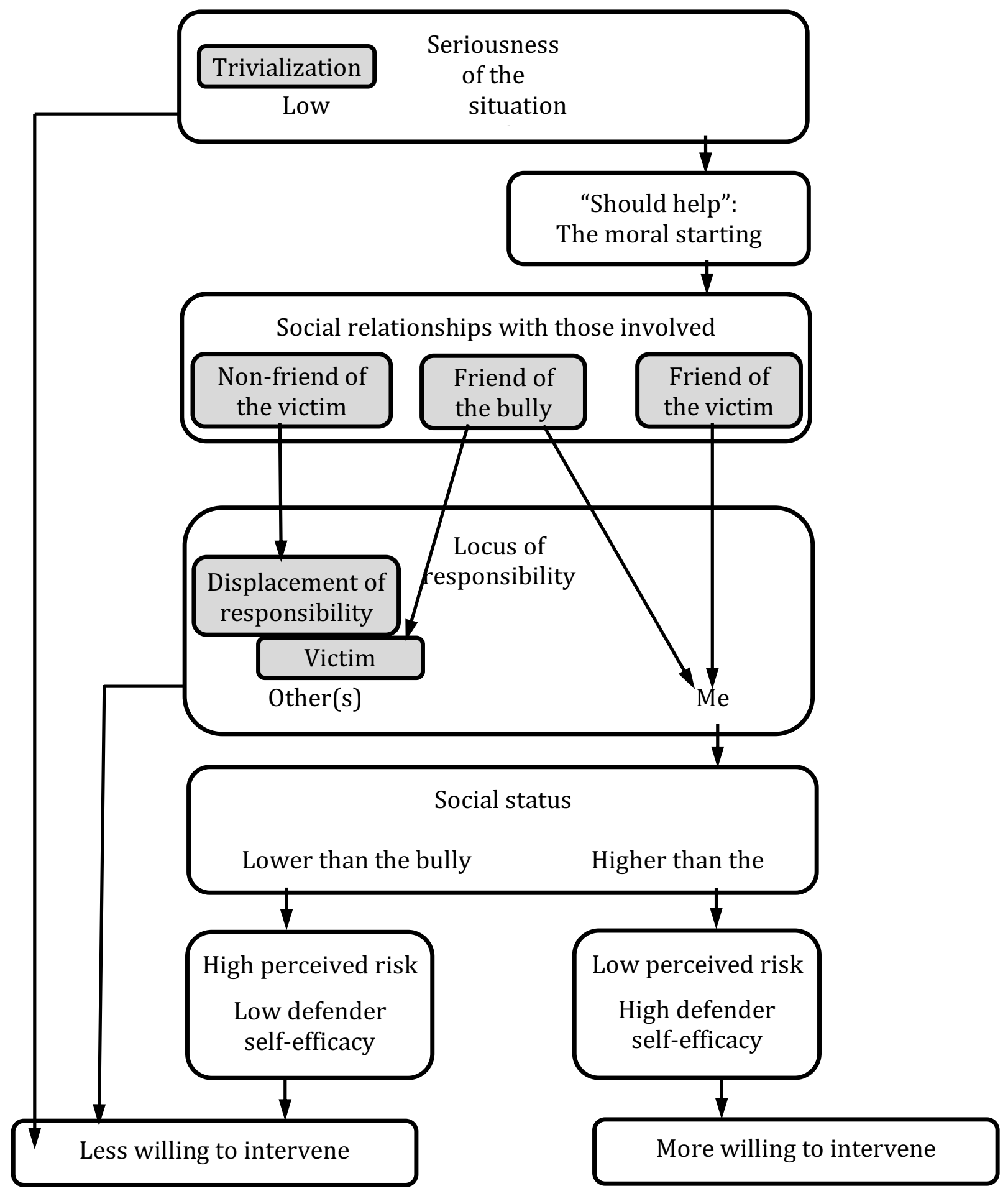

